A DESINSTITUCIONALIZAÇÃO NO CONTEXTO DA REFORMA PSIQUIÁTRICA E SEUS DESDOBRAMENTOS: UM RELATO SOBRE PRÁTICAS EM UM CAPS

Rocha, T. H. R.; Pena, B. V.; Manffré, M. C.; Jesus, L. M.

\title{
A DESINSTITUCIONALIZAÇÃO NO CONTEXTO DA REFORMA PSIQUIÁTRICA E SEUS DESDOBRAMENTOS: UM RELATO SOBRE PRÁTICAS EM UM CAPS
}

\author{
DOI - 10.32467/issn.1982-1492v16n1p1-16
}

\begin{abstract}
RESUMO
A história da atenção à saúde mental é marcada pela presença das instituições totais e existência de práticas que cerceavam direitos e reduziam a autonomia dos sujeitos. O advento da reforma psiquiátrica brasileira e da Luta Antimanicomial trouxeram várias mudanças no cenário de trabalho com o sujeito psicótico. À vista disso, o presente trabalho tem por objetivo discutir como têm ocorrido os processos de desinstitucionalização na atualidade, assim como investigar de que maneira os novos modelos de atenção adotados nos Centros de Atenção Psicossocial (CAPS) contrastam com as formas de tratamento que eram oferecidas nas instituições totais. Trata-se de um relato de experiência de caráter qualitativo- descritivo realizado dentro de um CAPS localizado em uma cidade do interior de Minas Gerais. Elaborou-se um panorama histórico e teórico que embasou as observações realizadas durante as visitas técnicas. Como resultado, foram estabelecidos quatro eixos temáticos. Esses visaram articular o usuário do CAPS com: (1) os profissionais; (2) as oficinas terapêuticas; (3) a sociedade e (4) a instituição. As análises realizadas apontaram que o CAPS aqui relatado tem caminhado em direção ao resgate do sujeito, considerando em sua atuação a promoção de autonomia e a retomada da subjetivação e socialização do mesmo.
\end{abstract}

Palavras-chave: atenção psicossocial; saúde mental; reforma psiquiátrica; desinstitucionalização.

\section{DEINSTITUTIONALIZATION IN THE CONTEXT OF PSYCHIATRIC REFORM AND ITS CONSEQUENCES: A STORY ABOUT PRACTICES IN A CAPS.}

\begin{abstract}
The history of mental health care is marked by the presence of total institutions and the existence of practices that curtail rights and reduce the autonomy of the subjects. The advent of the Brazilian psychiatric reform and of the anti-asylum movement brought several changes in the work scenario with the psychotic subject. In view of this, the present work aims to discuss how the deinstitutionalization processes have taken place in the present day, as well as to investigate how the
\end{abstract}




\title{
A DESINSTITUCIONALIZAÇÃO NO CONTEXTO DA REFORMA PSIQUIÁTRICA E
} SEUS DESDOBRAMENTOS: UM RELATO SOBRE PRÁTICAS EM UM CAPS

\author{
Rocha, T. H. R.; Pena, B. V.; Manffré, M. C.; Jesus, L. M.
}

new models of attention adopted in the Psychosocial Care Centers (CAPS) contrast with the forms of treatment that were offered in the total institutions. This is a qualitative-descriptive experience report carried out within a CAPS located in a city in the interior of Minas Gerais. A historical and theoretical panorama was elaborated that based the observations realized during the technical visits. As a result, four thematic axes have been established. These aimed at articulating the CAPS user with: (1) the professionals; (2) the therapeutic workshops; (3) society and (4) the institution. The analyzes carried out indicated that the CAPS reported here has been moving towards the rescue of the subject, considering in its action the promotion of autonomy and the resumption of subjectivation and socialization of the same.

Key words: psychosocial attention; mental health; psychiatric reform; desinstitutionalisation.

\section{LA DESINSTITUCIONALIZACIÓN EN EL CONTEXTO DE LA REFORMA PSIQUIÁTRICA Y SUS CONSECUENCIAS: UN RELATO SOBRE LAS PRÁCTICAS EN UN CAPS.}

\section{RESUMEN}

La historia de la atención a la salud mental está marcada por la presencia de las instituciones totales y la existencia de prácticas que cercaban derechos y reducían la autonomía de los sujetos. El advenimiento de la Reforma Psiquiátrica brasileña y antimanicomial trajo varios cambios en el trabajo de ajuste con el sujeto psicótico. A la vista de ello, el presente trabajo tiene por objetivo discutir cómo han ocurrido los procesos de desinstitucionalización en la actualidad, así como investigar de qué manera los nuevos modelos de atención adoptados en los Centros de Atención Psicosocial (CAPS) contrastan con las formas de tratamiento que se ofrecían en las instituciones totales. Se trata de un relato de experiencia de carácter cualitativo-descriptivo realizado dentro de un CAPS ubicado en una ciudad del interior de Minas Gerais. Se elaboró un panorama histórico y teórico que basó las observaciones realizadas durante las visitas técnicas. Como resultado, se establecieron cuatro ejes temáticos. Estos destinado para articular el usuario CAPS con: (1) los profesionales; (2) los talleres terapéuticos; (3) la sociedad y (4) la institución. Los análisis realizados apuntaron que el CAPS aquí relatado ha caminado hacia el rescate del sujeto, considerando en su actuación la promoción de autonomía y la retomada de la subjetivación y socialización del mismo.

Palabras clave: atención psicosocial; salud mental; reforma psiquiátrica; desinstitucionalización. 


\title{
A DESINSTITUCIONALIZAÇÃO NO CONTEXTO DA REFORMA PSIQUIÁTRICA E
} SEUS DESDOBRAMENTOS: UM RELATO SOBRE PRÁTICAS EM UM CAPS

\author{
Rocha, T. H. R.; Pena, B. V.; Manffré, M. C.; Jesus, L. M.
}

\section{INTRODUÇÃO}

Desde seu nascimento, o ser humano se encontra institucionalizado por diferentes locais e contextos como, por exemplo, a família. No decorrer da história de cada sujeito, outras instituições são colocadas em destaque, cada qual com sua função objetiva e normas próprias no meio social (Brito \& Dimenstein, 2008). Nesse sentido, tal como aponta Foucault (1979), as instituições aparecem enquanto forma de controle privilegiado sobre os corpos dos sujeitos. Logo, pode-se compreender que esses fenômenos institucionais perpassam a lógica da subjetivação de cada um. A fim de discutir sobre as instituições e a saúde mental, é importante analisar o que Goffman (1961) coloca como "instituições totais".

Uma instituição total configura-se enquanto um ambiente que agrupa sujeitos distintos entre si e os coloca em um mesmo cenário, excluindo-os da sociedade e, por consequência, controlando suas vidas e reprimindo sua singularidade. Um exemplo de instituição colocada pelo autor são os hospitais voltados para sujeitos com sofrimento psíquico e diagnóstico psiquiátrico, definido como "locais estabelecidos para cuidar de pessoas consideradas incapazes de cuidar de si mesmas e que são também uma ameaça à comunidade" (Goffman, 1961, p.16-17).

Para Foucault (1979), a principal função dessas instituições é a de disciplinar e normatizar, por meio de práticas que aprisionam e alienam. Dessa forma, tais estabelecimentos visam controlar os desvios dos sujeitos, efetuando sobre eles uma vigilância constante. Como aponta Benelli (2014), pode-se dizer que os diversos atores institucionais "não sabem o que fazem" (p.18), uma vez que é seu ser social que irá determinar sua consciência e suas práticas, sendo suas ações historicamente condicionadas e determinadas pelas condições sociais gerais de produção da existência.

Em A Lógica da Internação, o autor trabalha com a noção de que a institucionalização da vida do sujeito produz um tipo de subjetividade específica, a qual incide diretamente em sua constituição subjetiva, promovendo a explicitação de várias de suas possibilidades neuróticas, psicóticas e perversas. Prossegue trazendo as ideias de Foucault, que se atenta a outros aspectos tais como: a vigilância; os exames e testes que mensuram; a arquitetura dos edifícios; as regras escritas e as informais; e os demais detalhes presentes nas práticas cotidianas nas instituições. 


\title{
A DESINSTITUCIONALIZAÇÃO NO CONTEXTO DA REFORMA PSIQUIÁTRICA E
} SEUS DESDOBRAMENTOS: UM RELATO SOBRE PRÁTICAS EM UM CAPS

\author{
Rocha, T. H. R.; Pena, B. V.; Manffré, M. C.; Jesus, L. M.
}

Ainda para o autor, a produção do psiquismo no homem se dá não só por meio de discursos filosóficos e científicos, mas também por meio de práticas que tem como função a docilização e adestramento dos corpos humanos. Nesse sentido, o autor afirma:

A vigilância externa foi interiorizada como auto-observação, o confinamento e o silêncio levaram à introspecção, as normas, os regulamentos, as regras implícitas e explícitas mobilizaram a conduta, a postura correta; os relatórios dos casos, as provas, avaliações e exames obrigaram o indivíduo a se comportar adequadamente. Desse modo, as relações de poder engendraram a interioridade psicológica (Benelli, 2014, p.20).

Brito e Dimenstein (2008) destacam o papel dos hospitais, instituições que, até o século XVIII, tinham como principal intuito isolar os que perturbavam a sociedade, marginalizando-os e excluindo seus direitos como cidadãos. Oda e Dalgalarrondo (2004) colocam que, esses hospitais tinham, em sua teoria, a ideia de disponibilizar cuidados médicos, abrigo e alimento àqueles marginalizados, como por exemplo, os considerados como loucos.

A partir desses hospitais especializados no cuidado para com populações "indesejáveis" surge a ideia de hospício e asilos das Santas Casas de Misericórdia, que mais tarde foram legitimados pela lógica psiquiátrica. Ao serem retirados do local de direito social, essas pessoas eram depositadas nessas instituições que não possuíam o mínimo para garantir uma vida digna, uma vez que havia superlotação, condições precárias de sobrevivência e violência constantemente presentes; elementos esses que implicavam negativamente a situação dos internos (Brito \& Dimenstein, 2008).

Entre os fatores negativos dos hospitais especializados - os hospícios -, está o tratamento que se dava aos internados. Uma vez que não existiam psicofármacos, as técnicas utilizadas provocavam sofrimentos corpóreos e psíquicos que ilustravam, de fato, o despreparo para lidar com a humanização destas pessoas socialmente excluídas (Amarante, 2007). Assim, é nítido que as instituições voltadas para a saúde mental têm como representação de sua história fortes marcas de repressão, cerceamento do direito e redução da autonomia (Brito \& Dimenstein, 2008).

Essa lógica ditatorial dos hospitais vai ao encontro da instituição total enquanto "local [...] onde um grande número de indivíduos com situação semelhante, separados da sociedade [...] levam uma vida fechada e administrada" (Goffman, 1961, p.11). Logo, há o aniquilamento da subjetividade, uma vez que as mesmas regras, como horários e vestimentas, devem ser seguidas por todos os 


\title{
A DESINSTITUCIONALIZAÇÃO NO CONTEXTO DA REFORMA PSIQUIÁTRICA E SEUS DESDOBRAMENTOS: UM RELATO SOBRE PRÁTICAS EM UM CAPS
}

\author{
Rocha, T. H. R.; Pena, B. V.; Manffré, M. C.; Jesus, L. M.
}

internados, homogeneizando as demandas e objetificando os sujeitos, para atender um objetivo maior, o controle social.

A partir da década de 70, sob influência do movimento italiano da Psiquiatria Democrática, deu-se início à Reforma Psiquiátrica e ao movimento de desinstitucionalização no Brasil (Goulart, 2007). Tal movimento foi marcado por uma série de conquistas e medidas alcançadas na década de 80. Dentre elas a realização da $1^{\text {a }}$ Conferência Nacional de Saúde Mental no Rio de Janeiro em 1987; a criação do primeiro Centro de Atenção Psicossocial (CAPS) em São Paulo no mesmo ano; a intervenção na Casa de Saúde Anchieta em Santos (1988); e a entrada no Congresso Nacional do Projeto de Lei do deputado federal Paulo Delgado em 1989, que propunha a extinção dos manicômios e a oficialização da assistência psiquiátrica comunitária no Brasil. A Lei Paulo Delgado (Lei 10.216) foi sancionada em 2001 e promoveu grandes mudanças no modelo assistencial destinado aos pacientes portadores de sofrimento mental (Santos et al., 2000).

Esse movimento ganhou força com a implantação do Sistema Único de Saúde (SUS) e possibilitou que novos caminhos fossem traçados para a criação de um cuidado menos excludente, com uma lógica de assistência efetiva às demandas dos envolvidos (Goulart \& Durães, 2010).

Rotelli, De Leonardis e Mauri (2001) colocam a Reforma Psiquiátrica como um processo complexo que abrange diversos agentes e necessita que haja a desconstrução do saber psiquiátrico e da lógica hospitalocêntrica; uma vez que se faz necessário olhar para todas as dimensões do ser humano, considerando-o como ser político, cultural e social e não exclusivamente "patológico", característica essa restrita à dimensão biológica.

Tanto a reforma psiquiátrica brasileira quanto o movimento de Luta Antimanicomial trouxeram inúmeras mudanças que evidenciam a complexidade de um processo social que entrelaça dimensões simultâneas, que ora criam contradições, ora convergem. Basaglia (1979) coloca como ponto de vital importância o desafio que é dar vida ao sujeito com sofrimento psíquico, tendo sido este historicamente mortificado dentro das instituições manicomiais.

Diante disso, Amarante (2007) afirma que, no Brasil, o campo da saúde mental pode ser entendido como em pleno processo de transformação, uma vez que as antigas práticas de exclusão social, como as internações em manicômios, estão sendo substituídas por tratamentos que possibilitam e incentivam a manutenção dos vínculos familiares e sociais. Dentre os serviços que promovem a desospitalização se encontram as residências terapêuticas, os Núcleos de Atenção Psicossociais (NAPS), e os Centros de Atenção Psicossocial (CAPS). 


\title{
A DESINSTITUCIONALIZAÇÃO NO CONTEXTO DA REFORMA PSIQUIÁTRICA E
} SEUS DESDOBRAMENTOS: UM RELATO SOBRE PRÁTICAS EM UM CAPS

\author{
Rocha, T. H. R.; Pena, B. V.; Manffré, M. C.; Jesus, L. M.
}

O objetivo de recuperação do sujeito e construção de um novo pensamento humanitário orientou o surgimento dos Centros de Atenção Psicossocial (CAPS). Com isso, houve a conscientização da possibilidade e da importância da saída dos manicômios, escapando não somente do formato fechado dos hospitais, mas sobretudo das práticas alienantes de tratamento (Melo, 2012).

Os CAPS, segundo o Portal do Ministério da Saúde,

São instituições destinadas a acolher os pacientes com transtornos mentais, estimular sua integração social e familiar, apoiá-los em suas iniciativas de busca da autonomia, oferecerlhes atendimento médico e psicológico. Sua característica principal é buscar integrá-los a um ambiente social e cultural concreto, designado como seu "território", o espaço da cidade onde se desenvolve a vida quotidiana de usuários e familiares. Os CAPS constituem a principal estratégia do processo de reforma psiquiátrica (Ministério da Saúde, 2004, p.9).

Emerich (2007) corrobora com as preposições trazidas pelo Ministério da Saúde ao afirmar que é necessário ressaltar a importância da promoção da inserção do sujeito em diversas instâncias, como a política e a cultural, enquanto objetivo essencial das propostas de cuidado ofertadas nos CAPS.

Segundo a Portaria n. ${ }^{\circ} 336$ da Secretaria Nacional de Assistência à Saúde (2002), o CAPS é tido como local de tratamento a pessoas que necessitam de cuidados intensivos e promotores de vida. Além dessa definição inicial, outras características que necessitam ser colocadas são o caráter aberto e comunitário e a existência das equipes multiprofissionais e transdisciplinares, que possibilitam oferta de vínculo e assumem responsabilidade pelo cuidado.

Existem vínculos que estabelecem ligações entre os sujeitos e as entidades públicas, como os CAPS. Esses vínculos podem ter caráter visíveis ou não; sobre isso, Goffman (1961) coloca a identificação e a ligação emocional como essenciais, destacando a importância do "compromisso e adesão" de cada um.

Seria, portanto, um contrato pré-estabelecido a fim de garantir o cumprimento destas características (Goffman, 1961). Dessa forma, o CAPS ganha um caráter político dentro do cenário da saúde mental brasileira, desconstruindo, construindo e reconstruindo novas formas de compreensão dos fenômenos psíquicos e de tratamento de tais fenômenos (Ferreira et al., 2016). Onocko Campos (2001) retoma que é necessário enxergar esse usuário como um ser desejante e 


\title{
A DESINSTITUCIONALIZAÇÃO NO CONTEXTO DA REFORMA PSIQUIÁTRICA E
} SEUS DESDOBRAMENTOS: UM RELATO SOBRE PRÁTICAS EM UM CAPS

\author{
Rocha, T. H. R.; Pena, B. V.; Manffré, M. C.; Jesus, L. M.
}

possuidor de direitos, que um dia lhes foi retirado. Essa visão do ser possibilita a retomada da subjetivação e socialização do mesmo (Emerich, 2007).

\section{Método}

O presente estudo constitui-se enquanto um relato de experiência de caráter qualitativodescritivo realizado por três graduandas do curso de Psicologia de uma Universidade Federal, a partir de uma disciplina de estágio básico da matriz curricular do curso. Foram realizadas visitas técnicas a um Centro de Atenção Psicossocial (CAPS), localizado em uma cidade do interior do estado de Minas Gerais. Totalizaram-se nove visitas, com duração média de uma hora cada, compreendidas entre o mês de abril a junho do ano de 2018. Foram acompanhadas diversas atividades do CAPS relatado, incluindo oficinas terapêuticas e eventos. Além disso, durante as visitas houve interações com os usuários e profissionais do serviço. Durante esse período de visitação, aconteceram encontros para supervisão com o docente responsável pela disciplina.

Tal vivência teve por objetivo acompanhar as atividades cotidianas comuns ao CAPS e discutir, a partir de alguns referenciais teóricos que tratam da história dos tratamentos relativos à loucura, questões acerca da recuperação do sujeito esquecido frente às instituições totais e investigar como tem sido os desdobramentos do processo de desinstitucionalização na atualidade. Cabe ressaltar que a limitação do estudo se dá pelo fato de que as vivências ocorreram em apenas um CAPS, restando as observações restritas apenas a esta instituição. Contudo, é mister observar que tal imersão apenas neste ambiente possibilitou uma impressão qualitativamente mais significativa sobre as atividades realizadas.

\section{Resultados e discussão}

"Não basta derrubar os muros para acabar-se com os manicômios. O que é hospitalocêntrico são as práticas, mais sutis que as estruturas físicas" (Emerich, 2007, p.5). A Lei da Reforma Psiquiátrica coloca em primeiro plano a singularidade de quem sofre, priorizando a escuta, as relações e o cotidiano do usuário do Centro de Atenção Psicossocial (Estrella \& Mollica, 2015). As relações observadas no dia-a-dia do CAPS relatado nesse artigo vão ao encontro com a ideia de cuidado ao ser, desde a entrada na instituição, até sua vivência dentro desta, existe a busca por compreender quem é esse usuário dos serviços. Essa prioridade à relação para com o sujeito pôde ser observada tanto com os funcionários, como com os estagiários e os usuários que lá frequentam. 


\title{
A DESINSTITUCIONALIZAÇÃO NO CONTEXTO DA REFORMA PSIQUIÁTRICA E
} SEUS DESDOBRAMENTOS: UM RELATO SOBRE PRÁTICAS EM UM CAPS

\author{
Rocha, T. H. R.; Pena, B. V.; Manffré, M. C.; Jesus, L. M.
}

Para melhor organização do que foi observado, foram estabelecidos quatro eixos temáticos: a) Os usuários e os profissionais do CAPS; b) Os usuários e as oficinas terapêuticas do CAPS; c) O usuário do CAPS e a sociedade e d) O usuário do CAPS e a instituição:

\section{Os usuários e os profissionais do CAPS.}

Partindo da ideia da subjetivação do sofrimento em detrimento da clínica exclusivamente do sintoma, encontramos dentro do CAPS um maior cuidado quanto ao tratamento do usuário, fugindo da lógica hospitalocêntrica. Médicos, psicólogos, assistentes sociais, enfermeiros, entre outros profissionais, trabalham juntos, priorizando a humanização do cuidado e uma clínica que historiciza as condições etiológicas do sofrimento.

Se tomarmos o que Lacan (1969/1992) buscou desenvolver sobre as modalidades de tratamento do gozo a partir da teoria dos discursos, foi possível perceber um contraponto entre o que abriga a ordem do comando, no discurso do mestre, do que possa ser pensado pela sua oposição radical no discurso do analista. Bem distante da mestria, foram observadas práticas que fazem resistência ao desejo de dominação como, por exemplo, ao observamos o modo como era feita a medicalização dos usuários.

O modo de prescrição medicamentosa por parte dos médicos psiquiatras que ali trabalhavam, evidenciou a preocupação em desvencilharem-se da posição de detentores do saber uma vez que as práticas envolviam diretamente as demandas, anseios, resistências e o próprio saber em torno da doença constituído pelos próprios usuários do serviço. A posição de um suposto saber, - tal como alojado ao se fazer objeto causa do desejo no discurso do analista- permitia garantir aos sujeitos assistidos um lugar de inscrição enquanto agentes de seu próprio tratamento em uma narrativa própria, singular.

Além disso, é nítido o intercâmbio de conhecimentos que traz à tona a ideia de um sujeito plural. As práticas de tratamento ocorriam a partir de longas discussões clínicas com toda a equipe, descentralizada de qualquer agente que pudesse ocupar a posição de dominação. $O$ modo de tratamento cumpria o que Furtado e Campos (2005) apontam sobre a necessidade da transdisciplinaridade participativa entre a equipe e o sujeito em sofrimento psíquico.

De acordo com Passos et al. (2013), existe uma forte ligação entre os processos de gestão e os processos de promoção de saúde. O posicionamento da equipe do CAPS e a participação dos usuários apontam para a cogestão das práticas de tratamento. Produzir cogestão, nesses contextos, diz respeito 


\title{
A DESINSTITUCIONALIZAÇÃO NO CONTEXTO DA REFORMA PSIQUIÁTRICA E
} SEUS DESDOBRAMENTOS: UM RELATO SOBRE PRÁTICAS EM UM CAPS

\author{
Rocha, T. H. R.; Pena, B. V.; Manffré, M. C.; Jesus, L. M.
}

a criar espaços coletivos e democráticos onde antes imperavam modelos hierárquicos alicerçados na fragmentação do trabalho e privatização dos processos de atenção. Esse conceito visa situar horizontalmente os agentes (trabalhadores, gestores, usuários e familiares) do processo de produção de saúde, cogerindo o cuidado.

Afirma-se, portanto que a gestão do cuidado não deve ser localizada em funções centrais e totalitárias, uma vez que é preciso buscar lateralizar os pontos de vista dos agentes envolvidos. Dessa maneira, a cogestão coloca-se enquanto uma estratégia para a emergência do sujeito de direitos. O modelo de atendimento encontrado dentro do CAPS observado procura seguir esse princípio, uma vez que foge à lógica hierárquica, colocando as figuras que coabitam o local em um nível semelhante e permitindo o diálogo de fácil acesso. Foi possível observar que, diversas vezes os usuários do CAPS buscaram por profissionais específicos, por diversos motivos, sendo sempre prontamente atendidos.

Segundo Feitosa et al. (2012) uma das características que possibilita que o atendimento seja mais igualitário é a vestimenta dos profissionais. No CAPS a equipe profissional vestia-se de maneira comum, dispensando uniformes ou o já consagrado branco apropriado pelas ciências médicas. As roupas não demonstravam hierarquização diante os usuários, o que enriquece o tratamento e o acesso aos sujeitos.

No tratamento oferecido ficou nítida a busca por práticas que visavam garantir uma melhor estadia aos usuários do serviço. O que antes tomaria um caráter punitivo - como quando ações do usuário não estavam em acordo com as regras disciplinares da instituição - neste CAPS foi substituído por diálogos entre usuário e os profissionais. Essa nova postura permite uma maior assistência ao ser, criando vínculos mais estreitos entre quem trabalha dentro do CAPS e seus usuários (Feitosa et al., 2012). Inúmeros foram os comportamentos que poderiam ser vistos como transgressores da rotina da instituição durante o período de observação, porém, quando ocorriam, era por meio do diálogo concreto e direto que se estabeleciam acordos e explicações sobre a situação.

\section{Os usuários e as oficinas terapêuticas do CAPS}

Uma das práticas que garante a busca da singularidade e autonomia dos usuários são as oficinas terapêuticas. Essas são realizadas diariamente e contemplam diversas formas de expressão, instigando e colocando os sujeitos em movimento. Pode-se dizer que se colocam enquanto dispositivos importantes no processo da Reforma Psiquiátrica (Queiroz, Ferreira \& Silva, 2013) e 


\title{
A DESINSTITUCIONALIZAÇÃO NO CONTEXTO DA REFORMA PSIQUIÁTRICA E
} SEUS DESDOBRAMENTOS: UM RELATO SOBRE PRÁTICAS EM UM CAPS

\author{
Rocha, T. H. R.; Pena, B. V.; Manffré, M. C.; Jesus, L. M.
}

atuam no sentido de facilitar e mediar a vinculação dos usuários à instituição e ao tratamento, aumentando assim as possibilidades de investimento singular por parte destes.

Para Greco (2004), as oficinas terapêuticas são também ferramentas de reabilitação psicossocial, pois visam tanto o estímulo à criatividade e à expressividade, quanto a reinserção social; o que frequentemente foi observado nas relações estabelecidas que, via de regra, não permaneciam restritas ao espaço do CAPS.

As oficinas oferecidas variam entre atividades de desenho, artesanato, produção de sabão, e mais uma série de trabalhos que são produzidos nesse espaço. Assim,

O trabalho está relacionado ao efeito subjetivo daquela atividade, não àquilo que para outros define e justifica trabalho: a remuneração, o reconhecimento social ou a possibilidade de entrar no circuito das trocas sociais. (...) Trata-se de constituir um balizamento possível do real e do sujeito no real (Tenório, 2001, p.135).

A observação das oficinas promovidas no CAPS demonstrou que existiam claras divergências entre os usuários participantes: desde o modo pelo qual lidavam com as atividades propostas durante o processo, até a apresentação do objeto final, que conclui a oficina; o que se alinha com o que aponta Galletti (2004), ao afirmar que a oficina deve romper com a lógica naturalizada de espaço para tratamento. Essa deve ser um espaço para produzir diferenças, rompendo com a especialidade disciplinar e normalizadora, e se apoiando na perspectiva de reinvenção de modos de ser e viver.

Outro momento de evidência das divergências entre os usuários e da expressão de demandas próprias foi percebido durante a realização das oficinas de notícias. Nestas, os técnicos liam e comentavam assuntos pertinentes ao cotidiano, com especial enfoque à política e corrupção no país, haja visto serem os assuntos mais recorrentes no atual cenário midiático. Por vezes surgiam diferentes orientações políticas e opiniões. Essas logo eram mediadas com discussões que não buscavam silenciar os diferentes pontos de vista, pelo contrário, as discussões eram estimuladas sem que o teor das mesmas tomasse outras vias de expressão que não por meio da linguagem.

Foi constatado que os usuários possuem liberdade quanto à escolha e realização das oficinas, não sendo incomum encontrá-los decidindo qual atividade tem preferência em participar; ou recusando sua participação. Tal fato evidencia que os usuários desse CAPS são respeitados em suas decisões e existe a consideração de que não respondem todos da mesma maneira aos recursos terapêuticos fornecidos nesses serviços. 


\title{
A DESINSTITUCIONALIZAÇÃO NO CONTEXTO DA REFORMA PSIQUIÁTRICA E
} SEUS DESDOBRAMENTOS: UM RELATO SOBRE PRÁTICAS EM UM CAPS

\author{
Rocha, T. H. R.; Pena, B. V.; Manffré, M. C.; Jesus, L. M.
}

Queiroz, Ferreira \& Silva (2013) afirmam que muitos autores têm chamado atenção ao risco que as oficinas diárias correm de perder seu potencial de transformação quando se colocam como apenas mais uma tarefa a ser realizada pelos usuários, com o intuito de ocupar o tempo. Em uma oficina de pintura foi perceptível que, para alguns, o desenvolvimento da atividade se constituía de maneira mecânica, e não enquanto forma de expressão ou criação. Simultaneamente, cabe citar a observação de uma oficina de desenho na qual os usuários criavam obras de modo livre e, ao finalizarem, intitulavam a obra. Cada um deles empenhou-se em colocar um pouco de si em cada traço, nas histórias contadas e nas cores utilizadas.

Essas duas possibilidades de vivência das oficinas terapêuticas reiteram a importância de considerar a singularidade dos sujeitos e como essa interfere na resposta às intervenções terapêuticas propostas. Segundo Passos (2013), a participação ativa do sujeito no processo de promoção da sua saúde, ou seja, a cogestão do cuidado foge a causalidades e exige reposicionamentos subjetivos que dependem das condições concretas oferecidas no tratamento. Dito isso, conclui-se que as oficinas atuam nos modos de subjetivação e reconhecimento da alteridade, pois é nesse espaço que se experimenta e que se cria novas formas de relacionamentos e modos de ser (Lima, 2004).

\section{O usuário do CAPS e a sociedade}

No dia 18 de maio, dia da luta antimanicomial, foi realizada uma passeata que ocorreu pelas ruas da cidade. Profissionais, usuários e outros presentes se juntaram afim de "colocar o CAPS na rua", saindo da lógica da institucionalização e do encerramento da loucura no âmbito das instituições de saúde mental. Esta integração entre os usuários do CAPS e os demais membros da comunidade, em clima de festa e satisfação, foi vivenciada como um momento muito forte e simbólico. É necessário fazer caber a loucura na sociedade (Quinet, 2009), ao invés de alijá-la do espaço social e vilipendiar os direitos de sujeitos com sofrimento psíquico.

Situações como a presenciada na passeata que marca a luta antimanicomial permitem que se fortaleçam os laços e fique ainda mais visível o cuidado dos profissionais em proporcionar uma maior autonomia para esses sujeitos. Neste sentido, o valor e o acolhimento da sociedade permitem que o sujeito evolua dignamente, participando de forma ativa na comunidade que o cerca (Botelho \& Lima, 2015).

Para Firmo e Jorge (2015), ações que elevam o saber social dos usuários e de seus cuidadores são essenciais para o empoderamento dos sujeitos e sua melhor inserção social. Neste contexto, é importante salientar que é necessária a retomada de vínculos não só dentro do CAPS, mas também, 


\title{
A DESINSTITUCIONALIZAÇÃO NO CONTEXTO DA REFORMA PSIQUIÁTRICA E
} SEUS DESDOBRAMENTOS: UM RELATO SOBRE PRÁTICAS EM UM CAPS

\author{
Rocha, T. H. R.; Pena, B. V.; Manffré, M. C.; Jesus, L. M.
}

fora dele. Esse processo garante autonomia, aumentando diretamente a criação de um novo olhar para a sociedade e vice-versa, construindo a vida fora da instituição.

\section{O usuário do CAPS e a instituição}

O CAPS partilha da política "portas abertas", o que permite a construção de um espaço acolhedor incluso da cidade (Martinhago \& Oliveira, 2015). Porém, ainda que o novo modelo de cuidado à saúde mental rompa com inúmeras barreiras construídas pela história do movimento manicomial é necessário que seja alertado o fato de que, o CAPS ainda é uma instituição, ou seja, ainda que siga uma política de preocupação com o sujeito, possui regras e muros.

A respeito disso, deve-se colocar que não é possível a existência de uma desinstitucionalização dita absoluta. A vida em sociedade implica formas institucionalizadas de relação, e as instituições ocupam um lugar de suporte social. Deve-se então pensar na redefinição dos padrões de institucionalização, para que estes caminhem, na medida do possível, da totalização para maiores graus de autonomia (Martinhago \& Oliveira, 2015).

É comum o discurso dos usuários se voltarem para o CAPS como um local fechado, apesar de acolhedor. Nesse sentido é importante que haja atenção a novas formas de perceber a saúde mental, compreender a mudança enquanto um processo inacabado no presente momento e, em conjunto com políticas públicas, criar de um espaço digno que trabalhe com a potencialidade do sujeito ativo (Figueiró \& Dimenstein, 2010).

Por fim, cabe o questionamento sobre o risco que, "ao convidar os loucos e sua loucura para participar das trocas sociais no território da cidade, estejamos inadvertidamente, por meio de uma sutil ortopedia, forçando-os a adaptar-se aos modos de vida hegemônicos" (Lima \& Yasui, 2014, p.602). Fato este que evidencia o quão complexa se faz a real proposta da reforma psiquiátrica e da luta antimanicomial. As práticas dentro desses serviços devem estar sempre pautadas em questionamentos que buscam compreender se elas são de fato emancipatórias ou apenas reproduzem diferentes formas de domesticar a loucura.

\section{Considerações finais}

A partir do trabalho realizado, percebemos como é urgente "tentarmos transformar o doente mental morto no manicômio em pessoa viva, responsável pela própria vida” (Basaglia, 1979, p.60). Dessa forma, a vivência realizada e embasada nas ideias aqui discutidas, evidencia que o CAPS em questão, que está inserido no contexto brasileiro parece sustentar tal necessidade. 


\title{
A DESINSTITUCIONALIZAÇÃO NO CONTEXTO DA REFORMA PSIQUIÁTRICA E
} SEUS DESDOBRAMENTOS: UM RELATO SOBRE PRÁTICAS EM UM CAPS

\author{
Rocha, T. H. R.; Pena, B. V.; Manffré, M. C.; Jesus, L. M.
}

As mudanças provenientes da reforma atravessaram o campo político, social, cultural e clínico; configurando-se por meio das diretrizes e objetivos propostos aos novos modelos de atenção. Objetivos esses que não podem ser perdidos de vista, a fim de evitar que a burocracia e a institucionalização conservadora invadam os serviços substitutivos (Firmo \& Jorge, 2015). Apesar das conquistas, ainda há muito pelo que lutar, conquistar e ressignificar. Nesse sentido, retomamos Peter Pál Pelbart (1993) ao questionar:

Ao borrarmos essa fronteira simbólica e concreta entre a sociedade e seus loucos não estaremos, sob pretexto de acolher a diferença, simplesmente abolindo-a? Não estaremos, como um carinhoso abraço de urso, conjurando o perigo que os loucos representam? Não estaremos (...) domesticando a fera que os habita e nos livrando da estranheza que eles transmitem? (...) Será que a libertação do louco não corresponde, no fundo, a uma estratégia de homogeneização do social? (p.104)

Respondendo ao autor, Lima \& Yasui (2014) defendem que o atual cenário nos coloca diante de novos desafios: promover o acolhimento de pessoas em sofrimento psíquico sem domar a loucura e retirar dela sua potencialidade de romper códigos engessados e alienantes. Nesse sentido, com base nas vivências realizadas no CAPS aqui relatado, acreditamos que tal instituição se preocupa com as questões discutidas, investindo na promoção de um atendimento que busca construir espaços de produção de vida, potencialidades e singularidades, caminhando em direção ao resgate do sujeito, de sua individualidade e autonomia visando sua emancipação.

\section{REFERÊNCIAS}

Amarante, P.(2207). Saúde mental e atenção psicossocial. Rio de janeiro, RJ: Fiocruz.

Basaglia, F. (1979). A psiquiatria alternativa: contra o pessimismo da razão, o otimismo da prática. p.60. São Paulo, SP: Editora Brasil Debates.

Benelli, S. J. (2014). A lógica da internação: instituições totais e disciplinares (des)educativas. São Paulo: Editora UNESP. Disponível em: http://books.scielo.org/id/74z7q/pdf/benelli9788568334447.pdf. Acesso em 10 jun. 2018, 16:00.

Botelho, J. V.; Lima, M. V. (2015). Percepção das emoções dos usuários do CAPS II: Um relato de experiência. Revista de Psicologia, 27(2), p. 160-164. 


\title{
A DESINSTITUCIONALIZAÇÃO NO CONTEXTO DA REFORMA PSIQUIÁTRICA E SEUS DESDOBRAMENTOS: UM RELATO SOBRE PRÁTICAS EM UM CAPS
}

\author{
Rocha, T. H. R.; Pena, B. V.; Manffré, M. C.; Jesus, L. M.
}

Brito, M. A. M.; Dimenstein, M. (2008). Contornando as grades do manicômio: histórias de resistências esculpidas na instituição total. Aletheia, n. 28, p. 188-203.

Emerich, B. F. (2007). CAPS no território: Cuidado onde a vida acontece. Programa de Aprimoramento em Saúde Mental. Universidade Estadual de Campinas. Disponível em: < https://www.fcm.unicamp.br/fcm/sites/default/files/caps_no_territorio.pdf>. Acesso em 20 set. 2018, 19:00.

Estrella, R.; Mollica, M. (2015). O CAPS e a desinstitucionalização: Uma direção ética de trabalho. Ayvu: Revista de Psicologia, 1(2), p. 122-144.

Feitosa, K. M. A. et al. (2012). (Re)construção das práticas em saúde mental: compreensão dos profissionais sobre o processo de desinstitucionalização. Psicologia: teoria e prática, 14(1), p. 4054.

Ferreira, J. T. et al. (2016). Os Centros de Atenção Psicossocial (CAPS): Uma instituição de referência ao atendimento à saúde mental. Revista Saberes Rolim de Moura, 4 (1), p. 72-86.

Figueiró, R. A.; Dimenstein, M. (2010). O cotidiano de usuários de CAPS: Empoderamento ou captura? Revista de Psicologia, 22 (2), 431-446.

Firmo, A. A. M.; Jorge, M. S. B. (2015). Experiências dos cuidadores de pessoas com adoecimento psíquico em face à reforma psiquiátrica: produção do cuidado, autonomia, empoderamento e resolubilidade. Saúde Soc. São Paulo, 24 (1), p.217-231.

Foucault, M. (1979). Microfísica do poder. Organização e tradução de Roberto Machado. Rio de Janeiro. RJ: Edições Graal.

Furtado, J. P.; Campos, R. O. (2005). A transposição das políticas de saúde mental no Brasil para a prática nos novos serviços. Revista Latino-americana de Psicopatologia Fundamental, 8(1), p. 109122.

Galletti, M. C. (2004). Oficina em saúde mental: instrumento terapêutico ou intercessor clínico? Goiânia, GO: UCG.

Goffman, E. (1961). Manicômios, prisões e conventos. Pp. 11-17. São Paulo, SP: Perspectiva. 


\section{A DESINSTITUCIONALIZAÇÃO NO CONTEXTO DA REFORMA PSIQUIÁTRICA E}

SEUS DESDOBRAMENTOS: UM RELATO SOBRE PRÁTICAS EM UM CAPS

Rocha, T. H. R.; Pena, B. V.; Manffré, M. C.; Jesus, L. M.

Goulart, M. S. B.; Durães, F. (2010). A reforma e os hospitais psiquiátricos: histórias da desinstitucionalização. Psicologia \& Saúde, 22(1), p. 112-120.

Greco, M. G. (2004). Oficina: uma Questão de Lugar? In: COSTA, C. M.; FIGUEIREDO, A. C. (orgs.). Oficinas Terapêuticas em Saúde Mental - Sujeito, Produção e Cidadania. Rio de Janeiro, RJ: Contracapa.

Lacan, J. (1955- 1998). Variantes do tratamento padrão. In: Escritos. Rio de Janeiro, RJ: Jorge Zahar.

Lima, E. M. F. A.; Yasui, S. (2014). Territórios e sentidos: espaço, cultura, subjetividade e cuidado na atenção psicossocial. Saúde debate, 102. (38), p. 593-606.

Martinhago, F.; Oliveira, W. F. (2015). (Des)institucionalização: a percepção dos profissionais dos Centros de Atenção Psicossocial de Santa Catarina, Brasil. Saúde Soc. São Paulo, 24(4), p.12731284.

Melo, A. M. C. (2012). Apontamentos sobre a reforma psiquiátrica no Brasil. Cadernos Brasileiros de Saúde Mental, 8 (9), p. 84-95.

Ministério da Saúde. (2004). Saúde mental no SUS: os centros de atenção psicossocial. Brasília.

Moura, A. H. (2003). A Psicoterapia Institucional e o Clube dos Saberes. São Paulo, SP: Hucitec.

Oda, A. M. G. R.; Dalgalarrondo, P. (2004). O início da assistência aos alienados no Brasil ou importância e necessidade de estudar a história da psiquiatria. Revista Latino-americana de Psicopatologia Fundamental, 7(1), p. 128-159.

Passos, E. et al. (2013). Autonomia e cogestão na prática em saúde mental: o dispositivo da gestão autônoma da medicação (GAM). Aletheia, 41(1), p.24-38.

Pelbart, P. P. (1993). A nau do tempo-rei: sete ensaios sobre o tempo da loucura. pp. 104. Rio de Janeiro, RJ: Imago.

Queiroz, Y.S.; Ferreira, C.B.; Silva, A. M. F. (2013). Práticas em um CAPS de Minas Gerais: O relato de uma experiência. Revista da SPAGESP, 17(2),126-137. 


\title{
A DESINSTITUCIONALIZAÇÃO NO CONTEXTO DA REFORMA PSIQUIÁTRICA E
} SEUS DESDOBRAMENTOS: UM RELATO SOBRE PRÁTICAS EM UM CAPS

\author{
Rocha, T. H. R.; Pena, B. V.; Manffré, M. C.; Jesus, L. M.
}

Quinet, A. (2009). Psicose e laço social: esquizofrenia, paranoia e melancolia. Rio de Janeiro, RJ: Jorge Zahar.

Rotelli, F.; Leonardis, O. D.; Mauri, D. (2001). Desinstitucionalização, uma outra via: a reforma psiquiátrica italiana no contexto da Europa ocidental e dos países. In: NICÁCIO, M. F. (Org). Desinstitucionalização. 2. ed. (pp 17-59). São Paulo, SP: Hucitec.

Santos, N. S. S et. al. (2000). A autonomia do sujeito psicótico no contexto da reforma psiquiátrica brasileira. Psicologia: Ciência e Profissão, 20(4), p. 46-53.

Tenório, F. (2001). A psicanálise e a clínica da reforma psiquiátrica. (p. 135). Rio de Janeiro, RJ: Rios Ambiciosos, p.135.

Tiago Humberto Rodrigues Rocha: Psicólogo, Psicanalista, Doutor em Psicologia Social pela USPSP, Doutor em Psicologia pela Université de Rennes 2 (França), Professor Adjunto do Departamento de Psicologia da Universidade Federal do Triângulo Mineiro (UFTM). Uberaba, MG.

E-mail: tiagohrr@hotmail.com

Bárbara Vilela Pena: Graduanda do curso de Psicologia da Universidade Federal do Triângulo Mineiro (UFTM). Departamento de Psicologia. Uberaba, MG.

E-mail: babivilelap@gmail.com

Marina Capucci Manffré: Graduanda do curso de Psicologia da Universidade Federal do Triângulo Mineiro (UFTM). Departamento de Psicologia. Uberaba, MG. E-mail: mcm.marina@yahoo.com.br

Ludmila Madeira Jesus: Graduanda do curso de Psicologia da Universidade Federal do Triângulo Mineiro (UFTM). Departamento de Psicologia. Uberaba, MG. E-mail: ludmilamadeiraj@gmail.com 